\title{
Severe Modifications of Biological Markers in Late Neonatal Sepsis in a Very Low Birth Weight Due to Candida Iusitaniae
}

\author{
LEONARD NASTASE ${ }^{1 *}$, LUIZA RADULESCU2, MONICA LUMINITA LUMINOS2,3, MARIA MADALINA MERISESCU2,3, \\ GHEORGHITA J UGULETE ${ }^{2,3}$, SILVIA MARIA STOICESCU ${ }^{1,2}$ \\ ${ }^{1}$ National Institute for the Mother and Child Health Alessandrescu Rusescu, Polizu Maternity, 38-52 Gheorghe Polizu Str., \\ 011062, Bucharest, Romania \\ ${ }^{2}$ Carol Davila University of Medicine and Pharmacy, 37 Dionisie Lupu Str., 020021, Bucharest, Romania \\ ${ }^{3}$ National Institute of Infectious Diseases Prof. Dr. Matei Bals, 1 Dr. Calistrat Grozovici Str., 021105, Bucharest, Romania
}

\begin{abstract}
Neonatal sepsis is a major cause of neonatal mortality and morbidity in preterm, very low birth weight infants. Coagulase-negative staphylococcus and Candida spp. are among the most common causes of single infections and coinfections in neonates. Candida lusitaniae is rarely reported as an opportunistic pathogen in very low birth weight neonates. Early diagnosis and appropriate antifungal therapy can prevent morbidity and mortality in preterms especially in coinfections. Necrotizing enterocolitis is one of the most catastrophic gastrointestinal emergencies in premature infants in the intensive care neonatal unit, especially in preterm infants. Currently, the pathogenesis of necrotizing enterocolitis is believed to have multifactorial causes. We present the case of a very low birth weight preterm who developed necrotizing enterocolitis and sepsis caused by a coinfection of Coagulase-negative Staphylococcus and Candida lusitaniae.
\end{abstract}

Keywords: Candida lusitaniae, sepsis, very low birth weight preterm, coagulase-negative staphylococcus

Neonatal sepsis is a major cause of neonatal mortality and morbidity in preterm, (GA<37 weeks), very low birth weight infants (VLBW, BW $\leq 1500 \mathrm{~g}$ ). Coagulase-negative staphylococcus (CoNS) and Candida spp. are among the most common causes of single infections and coinfections in neonates [1, 2].

Invasive neonatal infections are responsible for 1.4 million deaths worldwide each year [3]. The prevalence of neonatal sepsis is inversely correlated with gestational age and birth weight and the survivors can have an increased risk of short and long neurologic sequelae [4 - 7].

The importance of Candida infections in neonatal intensive care units ( NICU) has been recognized in the last few years, as it is the third most common cause of late onset sepsis in very low birth weight preterms, after CoNS and Staphylococcus Aureus [8, 9].

Despite empirical antifungal therapy, related mortality remains considerably high, with even higher rates of longterm neurodevelopmental impairment in survivors [5, 8, 10].

Although most reported cases are due to Candida albicans, in recent years the incidence of non-albicans infections has increased [8]. Candida lusitaniae is rarely reported as an opportunistic pathogen in VLBW neonates [5].

NEC is the most common severe clinical gastrointestinal emergencies that affects premature infants in the NICU. Currently, the pathogenesis of NEC is believed to have multifactorial causes. Intestinal immaturity leads to a compromised intestinal epithelial barrier defense, altered vascular development and tonus. Caesarian section, formula feeding, antibiotics, exposure to luminal microbiota together with compromised mucosal barrier can lead to inflammation and sepsis [11].

CoNS, the most frequent constituent of the normal flora of the skin, are typical opportunists and they represent one of the major nosocomial pathogens with $S$. epidermidis and $S$. haemolyticus being the most significant species [12].
We present a case of a preterm that developed lateonset sepsis after coinfection with CoNS and Candida lusitaniae.

\section{Experimental part}

A 39-year-old patient, gravida 4, para 3, diagnosed with thrombophilia and preeclampsia was admitted in a level III maternity at 29 weeks and 6 days, 8 days prior to birth. She received treatment for pregnancy induced hypertension (PIH). The mean blood pressure remained high $(170 / 110 \mathrm{mmHg})$ as it did not respond to treatment and cesarean section was performed at 31 weeks of gestation. She had negative peripheric and central cultures throughout the pregnancy, prior, during the hospitalization and after birth.

The male infant had a birth weight of $1450 \mathrm{~g}$ (P50\%), a length of $45 \mathrm{~cm}$ (P75-90\%), a head circumference of 30 $\mathrm{cm}(\mathrm{P} 50-75 \%)$ and a ponderal index of $1.59(<\mathrm{P} 10 \%)$. Apgar scores were $7 / 8$ at 1 and $5 \mathrm{~min}$. Clinical examination in delivery room identified generalized cyanosis, diminished vesicular murmur, $\mathrm{HR}=140 \mathrm{bpm}$ and moderate tone.

The initial arterial blood gas showed metabolic acidosis and hypoglycemia which were corrected with intravenous (iv) bolus of normal saline and D10W solution. Blood cultures were sterile and the white blood count revealed 8 $160 / \mathrm{mm}^{3}, 31 \%$ neutrophils, $32 \%$ bands, $59 \%$ lymphocytes, $8 \%$ monocytes. The platelets count was $278000 / \mathrm{mm}^{3}$. He presented mild hypotension (blood pressure - BP $=50 / 21$ ) $30 \mathrm{mmHg}$ ) (fig. 1, table 1).

The infant was admitted in the NICU, placed at the thermal neutrality point in an incubator and received oxygen therapy as heated humidified high flow oxygen nasal canula, FiO2 of 0.25 , parenteral nutrition (TPN), prophylactic antibiotherapy (Penicillin and Colimycine). Due to mild hypotension and the metabolic acidosis ( $\mathrm{pH}=$ $7.15, \mathrm{BE}=-10.2 \mathrm{mmol} / \mathrm{L}, \mathrm{HCO}_{3}=19.3 \mathrm{mmol} / \mathrm{L}$, lactate $=$ $4.3 \mathrm{mmol} / \mathrm{L}$ ) enteral feeding was not started. 


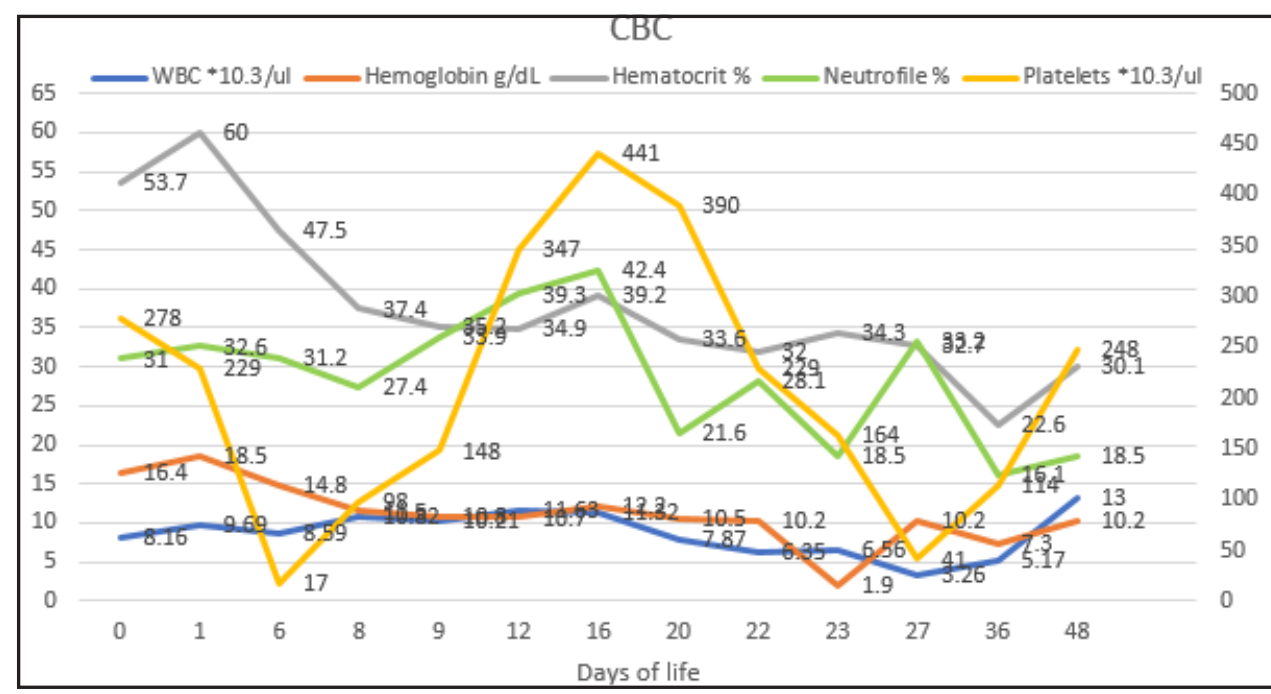

Fig. 1. Complete blood count (CBC) of the infant throughout his stay in the maternity

\begin{tabular}{|c|c|c|c|c|}
\hline Day & Leucocyteselem/mmc & Banded \% & Lymphocites \% & Monocites \% \\
\hline $1-3$ & $10800+/-4000$ & 47 & 34 & 3 \\
\hline $4-7$ & $8900+/-2900$ & 31 & 48 & 6 \\
\hline 14 & 14300 & 33 & 52 & 3 \\
\hline 1 month & 11000 & 26 & 59 & 4 \\
\hline
\end{tabular}

Table 1

NORMAL CBC VALUES ACCORDING TO BIRTHWEIGHT: 1200 - 1500G, [13]
At 24 hours of life he presented abdominal distension and bilious gastric residue with streaks of blood of approximately $4 \mathrm{~mL}$ in the absence of feeding, present bow el sounds, and he eliminated meconium after enema. Blood tests showed hemoglobin $=18.5 \mathrm{~g} / \mathrm{dL}$, hematocrit $=60 \%$, a white blood count of $9690 / \mathrm{mm}^{3}$, with $41 \%$ band neutrophils, $50 \%$ lymphocytes, $8 \%$ monocytes, with a platelet count of $229000 / \mathrm{mm}^{3}$, an oxygen saturation $(\mathrm{SpO} 2)>94 \%$, arterial partial pressure of oxygen $\left(\mathrm{PaO}_{2}\right)$ $>64 \mathrm{mmHg}$. No germs developed in the gastric lavage culture. He was kept nil per os (NPO) with TPN and Dopamine (3 $\mathrm{mcg} / \mathrm{kg} / \mathrm{minute}$ - mesenteric dose) and Tazobactam were added to the treatment.

On the 5th day of life blood tests showed, a white blood count of $8590 / \mathrm{mm}^{3}$ neutrophils, $31 \%$ bands, $59 \%$ lymphocytes and 9\% monocytes, CRP $=0.5 \mathrm{mg} / \mathrm{dL}(<1 \mathrm{mg} /$ $\mathrm{dL}), P C T=1.026 \mathrm{ng} / \mathrm{mL}(<0.5 \mathrm{ng} / \mathrm{mL})$ and a stool culture was positive for CoNS (fig. 2). The abdominal X-ray reveiled multiple dilated loops of gas filled bowel.

The stage diagnosis was necrotizing enterocolitis stage IA with CoNS. The pediatric surgery examination didn't find anything surgically acute. The rectal exam showed a supple rectal ampoule with faeces with mucus. The barium $X$-ray for the upper gastrointestinal tract was normal, as well as the abdominal ultrasound. Necrotizing enterocolitis diagnosis has been confirmed.
On the $6^{\text {th }}$ day a positive blood culture with Candida lusitaniae has been identified and the treatment was adjusted in accordance with Vancomycin and Fluconazole in therapeutic doses, NPO and TPN were maintained.

Similar laboratory results and positive stool culture for CoNS persists for another 8 days. Enteral feeding was initiated with delactosed formula for preterm infants (mothers' milk was contraindicated because of PIH treatment) and stopped after $24 \mathrm{~h}$ due to gastric residue with digested milk in a higher quantity than administrated.

On the 14th day of life the infant still presented feeding intolerance. Laboratory tests reveiled a sterile hemoculture and negative stool and gastric lavage cultures. The newborn was referred to pediatric surgery for reevaluation. Nothing surgically acute was found. On the $15^{\text {th }}$ day of life after enteral feeding had started, he presented bilious vomiting with blood strips. On the 22nd day, in the absence of enteral feeding, CRP rises ( $9.2 \mathrm{mg} \%$ ), PTC had a little higher than normal reference value $(0.81 \mathrm{ng} / \mathrm{mL})$, presepsin was normal $(732 \mathrm{pg} / \mathrm{mL})$, the stool culture was positive, again, for CoNS. The treatment with Vancomycin and Fluconazole continued.

Final diagnosis was late-onset sepsis with Candida lusitaniae, NEC with CoNS.

Enteral feeding was resumed on the $26^{\text {th }}$ day of life, at the beginning with age appropriate formula and then with

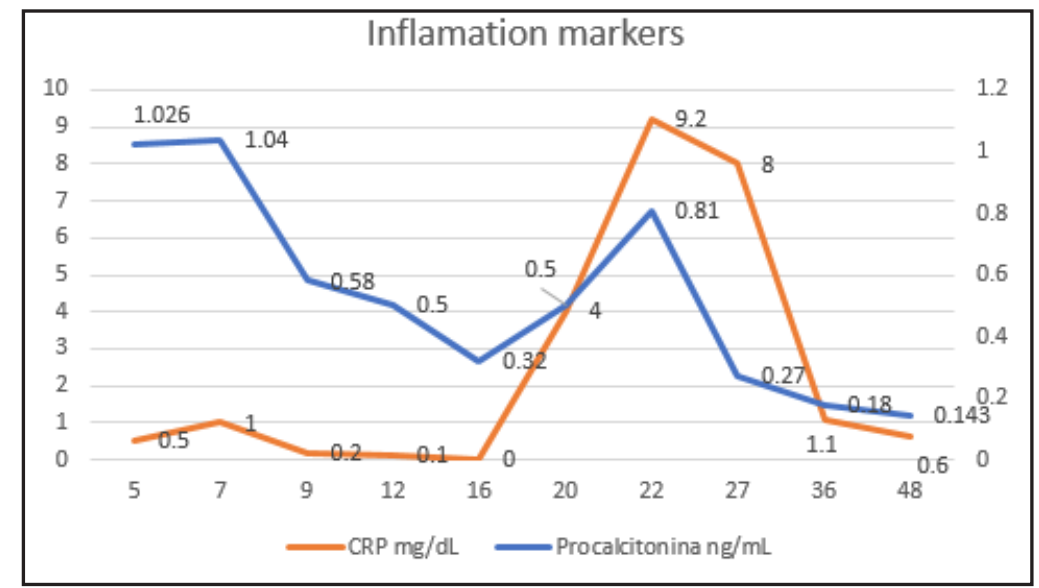

Fig. 2. The rise and fall of inflammation markers 
mothers' milk. The newborn was discharged at 51 days of life (38 postmenstrual weeks) at a weight of $2480 \mathrm{~g} \mathrm{(3^{ \text {rd } }}$ percentile), breast milk feeding.

\section{Results and discussions}

Neonatal sepsis is a clinical syndrome manifested through systemic signs of infection and isolation of a bacterial pathogen from the bloodstream. Although a consensus definition for neonatal sepsis is lacking. It is classified according to the infant's age at the onset of symptoms. Early-onset sepsis is defined as the onset of symptoms within the first $72 \mathrm{~h}$ of life and late-onset sepsis after $72 \mathrm{~h}$ of life for a preterm newborn [14].

The importance of Candida infections in the NICU has been recognized in the last few years, as it is the third most common cause of late onset sepsis in VLBW after CoNS and Staphylococcus Aureus [8].

CoNS and Candida are among the most common causes of single infections and coinfections in neonates after $72 \mathrm{~h}$ of age. The prevalence of neonatal sepsis is inversely correlated with gestational age and birth weight and therefore, in neonates, coinfection increases the rate of mortality threefold and results in significantly greater morbidity compared to those that result from single infections [1].

The positive cultures identified on the 5th and 6th day in the presented case suggest a nosocomial infection. The particular aspect is the bacteriological identification of CoNS and Candida lusitaniae in the same period of time, 5 th and 6th day respectively.

VLBW neonates have a high risk for invasive fungal infections [15]. Candida spp. infections are responsible for $10-12 \%$ of nosocomial sepsis in VLBW infants, with a cumulative incidence of $1-4 \%$ among all NICU admissions7. Out of most newborns admitted to the NICU, $75 \%$ are colonized with Candida by the first month [16]. This yeast is an important pathogen in this immunocompromised group of patients, due to the associated high rates of mortality of up to $30 \%$ and morbidity, including significant adverse neurodevelopmental outcomes [4, 5, 16].

Compared to relative peers without invasive candidiasis these rates are 2 to 6 times higher in neonates with invasive candidiasis $[5,10]$.

The Candida species most commonly isolated from neonatal patients with invasive candidiasis is Candida albicans. However, recently there has been a significant rise in isolation rates for other species [17].

At first identified as Candida parapsilosis var. obtuse in 1954 [18], it was renamed Candida lusitaniae in 1959 [14]. Since it was first identified in 1979 in the context of an opportunistic infection in a patient with acute leukemia [20], Candida lusitaniae has been recovered from various sites in the human body including urine, bronchoalveolar lavage fluid, blood and peritoneal fluid, as well as from the kidney, vagina and the skin [21-25], mostly from immunocompromised patients including HIV/AIDS, cancer as well as neonatal or pediatric patients.

Candida lusitaniae is a pathogen more commonly associated to a group of immunocompromised patients, not normally present in the NICU, especially in the case of premature newborn infants, an aspect highlighted by the rarity of cases described in literature (table 2).

The development of the systemic candidiasis depends on the association between the hosts risk factors and the virulence of the candida species [33].

Usually affected neonates are admitted in the NICU and they require invasive therapies like central vascular catheters, endotracheal intubation and ventilation and are exposed to broad-pectrum antibiotherapy and parenteral nutrition [34].

It is also known that the transformation of Candida lusitaniae in a pathogen organism is favored by the presence of NEC, especially because preterms are compromised hosts for whom an opportunistic organism such as candida is a serious threat [35, 36].

Table 2

PUBLISHED STUDIES REPORTING CANDIDA LUSITANIAE FUNGEMIA IN PRETERM NEONATES

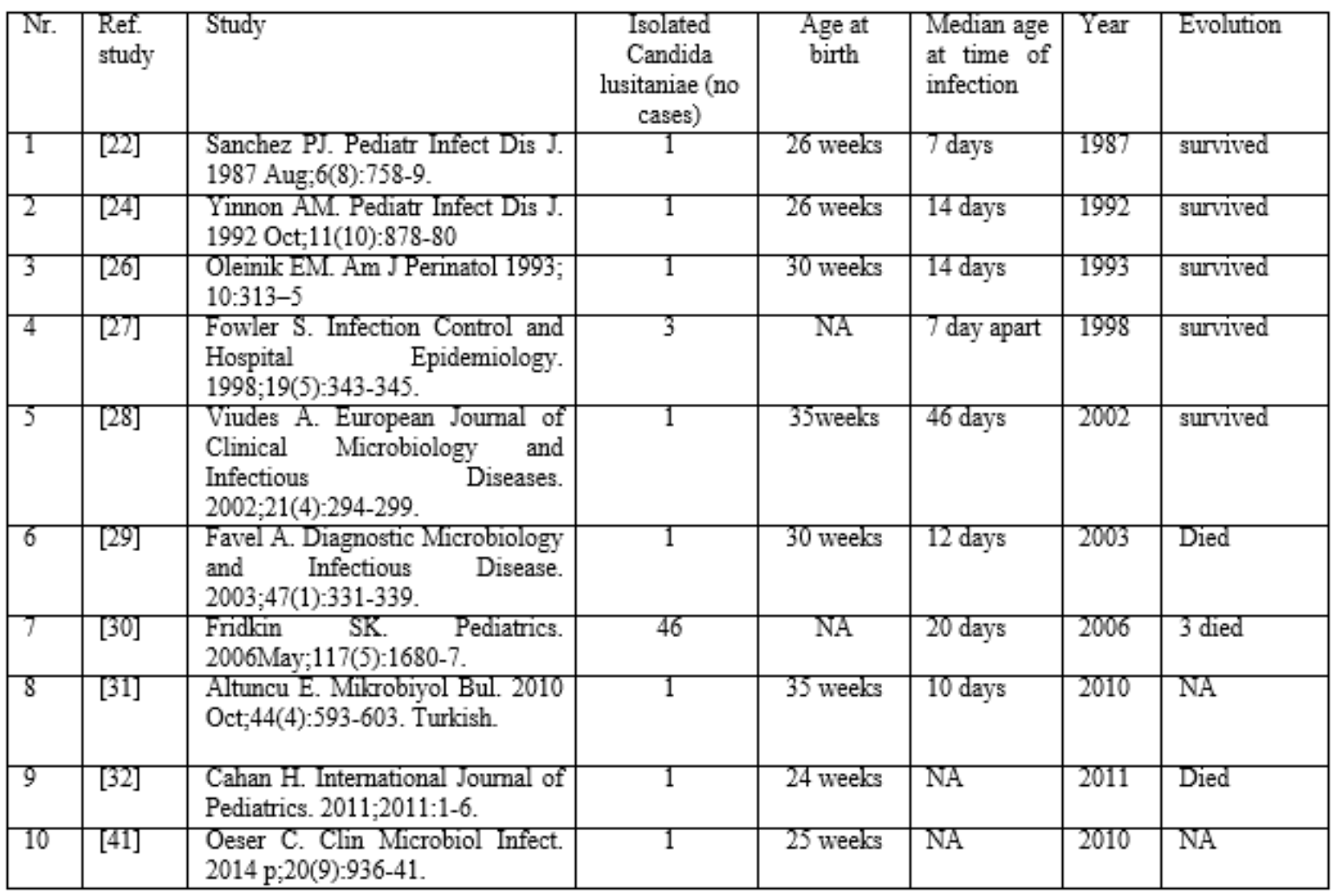


In the presented case the presence of CoNS in newborns stool cultures allowed the transformation of this species into a pathogen. Or perhaps the colonization of the new born emerged as a sum of events including the cesarean section, the admission into NICU where he was subject to multiple manipulations. Important facts to consider in this case are the absence of umbilical or central catheters and lack of mechanical ventilation unlike the identified cases in literature [ $36-40]$.

Necrotizing enterocolitis (NEC) is one of the most catastrophic gastrointestinal emergencies in premature infants in the NICU, especially in preterm VLBW infants. Currently, the pathogenesis of NEC is believed to have multifactorial causes. Intestinal immaturity leads to a compromised intestinal epithelial barrier defense, altered vascular development and tonus. Caesarian section, formula feeding, antibiotics, exposure to luminal microbiota together with compromised mucosal barrier can lead to inflammation and sepsis [11].

In the current case, a preterm of 31 weeks gestation, VLBW, could have the intestinal barrier affected during the perinatal period, considering the maternal pathology, in association with risk factors, caesarean section and formula feeding $[40,42]$.

According to the new NEC, the lining alteration is the result of the concomitant effect of the delay in nutrition initiation, the administration of antibiotics, the lack of use of mothers' milk, after an initial possible intrauterine alteration due to changing of mesenteric blood flows secondary to maternal hypertension [42, 43].

Bowel damage is manifested as increased levels of lymphocytes from birth, values that persist if there is a clinical manifestation and positive culture for CoNS. On the other hand, an immature immune system partially able to identify pathogens is altered by the administered antibiotics. And so innate immune cells, lymphocytes, respond nonspecifically and do not provide long-term immunity [44].

The lymphomonocytosys present here from the first 24 hours, may be considered a first non-specific inflammatory answer by an immature immune system [45].

Furthermore, preterm infants who receive intravenous boluses, like in this case, associate greater risk to develop NEC [46].

Gastric residuals suggest feeding intolerance, however, it only indicates compromise of intestinal integrity when the residuals are either bloody or in excess with more than $30-50 \%$ of the previous feed $[43,47]$.

The NEC typical clinical pattern in the case of a preterm is determined by the terminal ileum localization manifested through abdominal distension, gastric residual and vomiting. In our case, the digestive intolerance was present form the first 24 hours of life despite a good oxygenation and a severe respiratory pathology that could have affected the mesenteric oxygenation [42].

In the same time maternal pathology did not allow initiation of enteral feeding with breast milk due to antihypertensive treatment, so age appropriate formula was used.

Infants who develop NEC have microbial dysbiosis compared to those who do not and VLBW associate a higher risk due to gastrointestinal dysfunction, sepsis, transfusions, oxygen toxicity and other pathophysiological conditions that affect the normal microbiota $[43,48]$.

Culture based studies have clearly demonstrated differences in fecal bacteria up to $72 \mathrm{~h}$ before the onset of NEC [49]. In this case clinical symptoms prior the cultures results. $\mathrm{C}$ reactive protein or/and procalcitonin are raised in stage II and III of NEC but do not offer much in the way of sensitivity and specificity [43, 48].

Antifungal prophylaxis was started in the 3rd day of antibiotic therapy, but despite this, Candida lusitaniae was identified in the 6th day. The clinical picture was not fully resolved until after a 21 day antifungal and antistaphylococcal treatment.

\section{Conclusions}

In the presented case the following scenario is possible. NEC with a known NICU pathogen for the last 30 years, CoNS respectively, favors the appearance of sepsis with a fungal pathogen in a patient with depressed immunity. The treatment was effective so that digestive tolerance was established after antifungal treatment was started. The mean weight gain after establishing digestive tolerance was $29 \mathrm{~g} /$ day.

Early enteral nutrition with breast milk appears to be the key to prevent these serious diseases for these utterly defenseless organisms as the preterms.

\section{References}

1. VENKATESH MP, PHAM D, FEIN M, KONG L, WEISMAN LE. Neonatal coinfection model of coagulase-negative Staphylococcus (Staphylococcus epidermidis) and Candida albicans: fluconazole prophylaxis enhances survival and growth. Antimicrob Agents Chemother. 2007 Apr;51(4):1240-5

2. STOLL BJ, HANSEN N, FANAROFF AA, et al. Late-onset sepsis in very low birth weight neonates: the experience of the NICHD Neonatal Research Network. Pediatrics. 2002; 110(2 Pt 1):285-291

3. SILVA NBS, MENEZES RP, BRITO MO, ALVES PGV, PEDROSO RS, RÖDER DVDB. Sepsis Neonatal: Epidemiology, Etiology and Risk Factors. Adv Biotech \& Micro. 2017; 4(2): 555632

4. EICHENWALD E, HANSEN A, MARTIN C, STARK A. Cloherty and Stark's manual of neonatal care. 8th ed. Philadelphia: Wolters Kluwer; 2017, pg 684.

5. GAUTAM, M. K.; LI, J. Neonatal Candida Lusitaniae Septicemia. J Nepal Paediatr Soc 2014;34(2):160-162

6. GEPHART SM, MCGRATH J M, EFFKEN JA, HALPERN MD. Necrotizing enterocolitis risk: state of the science. Adv Neonatal Care. 2012 Apr;12(2):77-87;

7. BERKHOUT DJC, KLAASSEN P, NIEMARKT HJ, DE BOODE WP, COSSEY V, VAN GOUDOEVER et al. Risk Factors for Necrotizing Enterocolitis: A Prospective Multicenter Case-Control Study. Neonatology. 2018;114(3):277-284.

8. LEIBOVITZE. Strategies for the Prevention of Neonatal Candidiasis. Pediatrics \& Neonatology. 2012;53(2):83-89.

9. CAMACHO-GONZALEZ A, SPEARMAN PW, STOLL BJ. Neonatal infectious diseases: evaluation of neonatal sepsis. Pediatr Clin North Am. 2013 Apr;60(2):367-89

10. BOTERO-CALDERON L, BENJ AMIN DK, COHEN-WOLKOWIEZ M. Advances in the treatment of invasive neonatal candidiasis. Expert opinion on pharmacotherapy. 2015;16(7):1035-1048

11. TANNER SM, BERRYHILL TF, ELLENBURG JL, JILLING T, CLEVELAND DS, LORENZRG, MARTIN CA. Pathogenesis of necrotizing enterocolitis: modeling the innate immune response. Am J Pathol. 2015J an;185(1):4-16.

12. BECKER K, HEILMANN C, PETERS G. Coagulase-negative staphylococci. Clin Microbiol Rev. 2014 Oct;27(4):870-926.

13. ESAN AJ . Hematological differences in newborn and aging: a review study. Hematol Transfus Int J. 2016;3(3):178 190.

14. NG S, STRUNK T, JIANG P, MUK T, SANGILD PT AND CURRIE A (2018) Precision Medicine for Neonatal Sepsis. Front. Mol. Biosci. 5:70

15. ERICSON JE, BENJAMIN DK. Fluconazole prophylaxis for prevention of invasive candidiasis in infants. Current opinion in pediatrics. 2014;26(2):151-156.

16. BENDEL M. Nosocomial Neonatal Candidiasis. Pediatr Infect Dis J 2005;24: 831-832 
17. FU J, DING Y, WEI B, WANG L, XU S, QIN P, WEI L, JIANG L. Epidemiology of Candida albicans and non-C.albicans of neonatal candidemia at a tertiary care hospital in western China. BMC Infect Dis. 2017 May 6;17(1):329

18. SANCHEZ PJ, COOPER BH. Candida Iusitaniae: sepsis and meningitis in a neonate. Pediatr Infect Dis J 1987; 6:758-9.

19. HOLZSCHU DL, PRESLEY HL, MIRANDA M, PHAFF HJ . Identification of Candida lusitaniae as an opportunistic yeast in humans. J Clin Microbiol. 1979 Aug; 10(2):202-5.

20. PAPPAGIANIS D, COLLINS MS, HECTOR R, REMINGTON J. Development of resistance to amphotericin $B$ in Candida lusitaniae infecting a human. Antimicrob Agents Chemother. 1979 Aug; 16(2):1236.

21. FU J, DING Y, WEI B, WANG L, XU S, QIN P, WEI L, JIANG L. Epidemiology of Candida albicans and non-C.albicans of neonatal candidemia at a tertiary care hospital in western China. BMC Infect Dis. 2017 May 6;17(1):329

22. SANCHEZ PJ, COOPER BH. Candida lusitaniae: sepsis and meningitis in a neonate. Pediatr Infect Dis J 1987; 6:758-9.

23. BENJ AMIN D, STOLL B, GANTZM, WALSH M, SANCHEZP, DAS A et al. Neonatal Candidiasis: Epidemiology, Risk Factors, and Clinical Judgment. PEDIATRICS. 2010;126(4):e865-e873.

24. YINNON AM, WOODIN KA, POWELL KR. Candida lusitaniae infection in the newborn: case report and review of the literature. Pediatr Infect Dis 1992; 11:878-80.

25. WILLIAM G. MERZ WG, KHAZAN LU, JABRA-RIZK MA, WU LC, OSTERHOUT GJ, LEHMANN PF. Strain Delineation and Epidemiology of Candida (Clavispora) lusitaniae. Journal of Clinical Microbiology 1992 (2) 30:449-454.

26. OLEINIK EM, DELLA-LATTA P, RINALDI MG, etal. Candida lusitaniae osteomyelitis in a premature infant. Am J Perinatol 1993; 10:313-5

27. FOWLER S, RHOTON B, SPRINGER S, MESSER S, HOLLIS R, PFALLER M. Evidence for Person-to-Person Transmission of Candida lusitaniae in a Neonatal Intensive-Care Unit. Infection Control and Hospital Epidemiology. 1998;19(5):343-345.

28. VIUDES A, PEMAN J, CANTON E, SALAVERT M, UBEDA P, LOPEZRIBOT J. Two Cases of Fungemia due to Candida lusitaniae and a Literature Review. European J ournal of Clinical Microbiology and Infectious Diseases. 2002;21(4):294-299

29. FAVEL A, MICHEL-NGUYEN A, PEYRON F, MARTIN C, THOMACHOT $L$, DATRY A et al. Colony morphology switching of Candida lusitaniae and acquisition of multidrug resistance during treatment of a renal infection in a newborn: case report and review of the literature. Diagnostic Microbiology and Infectious Disease. 2003;47(1):331-339.

30. FRIDKIN SK, KAUFMAN D, EDWARDSJR, et al. Changing incidence of Candida bloodstream infections among NICU patients in the United States: 1995-2004. Pediatrics. 2006; 117:1680-1687

31. ALTUNCU E, BILGEN H, CERIKCIOGLU N, ILKI A, ULGER N, BAKYR $M$ et al. Neonatal Candida infections and the antifungal susceptibilities of the related Candida species. Mikrobiyol Bul. 2010 Oct;44(4):593603. Turkish.

32. CAHAN H, DEVILLE J. Outcomes of Neonatal Candidiasis: The Impact of Delayed Initiation of Antifungal Therapy. International J ournal of Pediatrics. 2011;2011:1-6.

33. POLIN R, DENSON S, BRADY M. Strategies for Prevention of Health Care-Associated Infections in the NICU. Pediatrics. 2012;129(4) :e1085e1093.
34. KAUFMAN D. Challenging issues in neonatal candidiasis. Current Medical Research and Opinion. 2010;26(7):1769-1778.

35. BARTON M, O'BRIEN K, ROBINSON JL, DAVIES DH, SIMPSON K, ASZTALOS E et al. Invasive candidiasis in low birth weight preterm infants: risk factors, clinical course and outcome in a prospective multicenter study of cases and their matched controls. BMC Infect Dis. 2014 J un 12;14:327

36. PARRA-HERRAN CE, PELAEZ L, SOLA JE, URBIZTONDO AK, RODRIGUEZ MM. Intestinal candidiasis: an uncommon cause of necrotizing enterocolitis (NEC) in neonates. Fetal and pediatric pathology. 2010;29(3):172-180

37. FU J, DING Y, WEI B, WANG L, XU S, QIN P, WEI L, JIANG L. Epidemiology of Candida albicans and non-C.albicans of neonatal candidemia at a tertiary care hospital in western China. BMC Infect Dis. 2017 May 6;17(1):329

38. BENJ AMIN D, STOLL B, GANTZ M, WALSH M, SANCHEZP, DASA et al. Neonatal Candidiasis: Epidemiology, Risk Factors, and Clinical Judgment. PEDIATRICS. 2010;126(4):e865-e873.

39.*** Polin. Hematology, Immunology and Infectious Disease: Neonatology Questions and Controversie, $1^{\text {st }}$ edition, 2018, pg 263

40. GEPHART SM, MCGRATH J M, EFFKEN J A, HALPERN MD. Necrotizing enterocolitis risk: state of the science. Adv Neonatal Care. 2012 Apr;12(2):77-87

41. OESER C, VERGNANO S, NAIDOO R, ANTHONY M, CHANG J , CHOW $P$ et al. Neonatal Infection Surveillance Netw ork (neonIN). Neonatal invasive fungal infection in England 2004-2010. Clin Microbiol Infect. 2014 Sep;20(9):936-41.

42. MELANIA PUDDU et al. From the old NEC to the new NECs. Journal of Pediatric and Neonatal Individualized Medicine 2014;3(2):e030245.

43. HAQUE K. Necrotizing enterocolitis - Some things old and some things new: A comprehensive review. J ournal of Clinical Neonatology. 2016;5(2):79.

44. NUPPONEN I, KUULIALA A, SIITONEN S, REPO H, KUULIALA K. Cord Blood Monocytes, Neutrophils and Lymphocytes from Preterm and Full-Term Neonates Show Multiple Aberrations in Signalling Profiles Measured Using Phospho-Specific Whole-Blood Flow Cytometry. Scandinavian Journal of Immunology. 2013;78(5):426-438. 45. GOEDICKE-FRITZ S, HARTEL C, KRASTEVA-CHRIST G, KOPP M, MEYER S, ZEMLIN M. Preterm BirthAffects the Risk of Developing Immune-Mediated Diseases. Frontiers in Immunology. 2017;8:1266. 46. ASLAM A, VINCER M, ALLEN A, IMANULLAH S, O'CONNELL CM. Long-term outcomes of saline boluses in very preterm infants. J Neonatal Perinatal Med. 2018;11(3):317-321.

47. PARKER L, TORRAZZA RM, LI Y, TALAGA E, SHUSTER J, NEU J. Aspiration and Evaluation of Gastric Residuals in the NICU: State of the Science. The J ournal of perinatal \& neonatal nursing. 2015;29(1):5159.

48. PAMMI M, COPE J, TARR PI, WARNER BB, MORROW AL, MAI V, GREGORY KE, KROLL J S, MCMURTRY V, FERRIS MJ , ENGSTRAND L, LILJ A HE, HOLLISTER EB, VERSALOVIC J, NEU J. Intestinal dysbiosis in preterm infants preceding necrotizing enterocolitis: a systematic review and meta-analysis. Microbiome. 2017 Mar 9;5(1):31.

49. PATEL RM, DENNING PW. Intestinal microbiota and its relationship with necrotizing enterocolitis. Pediatr Res. 2015 Sep;78(3):232-8

50. NASTASE, L., LUMINOS, M., JUGULETE, G., MERISESCU, M.M., STOICESCU, S.M., Fetal Cerebral Monitoring During the Second Stage of Labor,.Rev. Chim. (Bucharest), 69, no. 11, 2018, p. 3072

Manuscript received: 5.10 .2018 